\title{
latrogenic Intravascular Foreign Body Retrieval in a Neonate
}

\author{
Manish Kumar Yadav ${ }^{1, \odot}$ Ramakrishna Pillai ${ }^{2}$ Madhavan Unni ${ }^{3}$ Shaji Palangadan ${ }^{4}$ Naveen Jain ${ }^{5}$
}

${ }^{1}$ Division of Interventional Radiology, Department of Radiology, Kerala Institute of Medical Sciences, Trivandrum, Kerala, India

2Department of Cardiology, Kerala Institute of Medical Sciences, Trivandrum, Kerala, India

${ }^{3}$ Department of Radiology, Kerala Institute of Medical Sciences, Trivandrum, Kerala, India

${ }^{4}$ Department of Cardiothoracic and Vascular Surgery, Kerala

Institute of Medical Sciences, Trivandrum, Kerala, India

${ }^{5}$ Department of Neonatology, Kerala Institute of Medical Sciences, Trivandrum, Kerala, India

J Clin Interv Radiol ISVIR:2020;4:130-132

\author{
Address for correspondence Manish Kumar Yadav, MBBS, DMRD, \\ DNB, FNVIR, 12A, Ivory, SFS Cyberpalms, Bypass Road, Near MGM \\ School, Trivandrum 695583, Kerala, India \\ (e-mail: drmanishyadav@yahoo.co.in).
}
Abstract
Keywords
- neonate
- intravascular foreign body
- retrieval

This is a short communication demonstrating a unique method of intravascular foreign body retrieval by grasp from inside technique in a neonate.

\section{Introduction}

We report a case of percutaneous retrieval of a misplaced iatrogenic foreign body. A 34-week preterm newborn was under admission in the neonatal intensive care unit for persistent hypoglycemia manifesting soon after birth and was recovering from the same. Patient had a 6-French umbilical vein catheter placed during the initial admission period for fluid management. On day 7, when the patient had made good recovery, it was decided to remove the umbilical catheter. During the process of cutting the sutures to unfasten the catheter, the catheter tip got inadvertently cut and the catheter was no longer accessible for removal by simple pull out maneuver. A mini cutdown of the umbilical vein was attempted by surgical colleagues as the catheter was still palpable just cranial to the umbilicus. During the surgical manipulation of the site for stay sutures on the umbilical vein, the catheter migrated further cranially and was no longer palpable. At this point ultrasound demonstrated the position of the lower end of catheter in the segment of the umbilical vein in the fissure for ligamentum teres. It was decided to attempt percutaneous retrieval and to consider surgical exploration as second option.

Low-dose fluoroscopy done in cathlab showed lower end of catheter along the lower edge of liver and the catheter passing through ductus venosus, IVC, right atrium then through the patent foramen ovale into the left atrium and the tip was seen into the right superior pulmonary vein.

Initial attempts were made to cannulate the umbilical vein and the umbilical catheter within 0.014" (VersaTurn F, Abbott Vascular). However these attempts were unfruitful due to low support of the wire and collapsed umbilical vein. 0.014 " wire failed to travel any further in umbilical vein and repeatedly entered peritoneal cavity; hence, it was decided to use a sheath touching the lower end of catheter so that the 0.014 " wire could easily enter into the catheter $(\boldsymbol{-}$ Fig. 1 ). The umbilical vein was catheterized subsequently under direct vision using a short 0.025 " guidewire, which was navigated into the lumen of the displaced umbilical catheter. A short 0.025 " wire was chosen to support the sheath placement. Although the entry of 0.025 " guidewire into lumen was not deliberate, however, due to the vein collapsing over the catheter,
DOI https://doi.org/

$10.1055 / \mathrm{s}-0040-1710151$

ISSN 2457-0214.
Copyright $\odot 2020$ Indian Society of Otology
License terms

() (1) $\ominus \circledast$ 


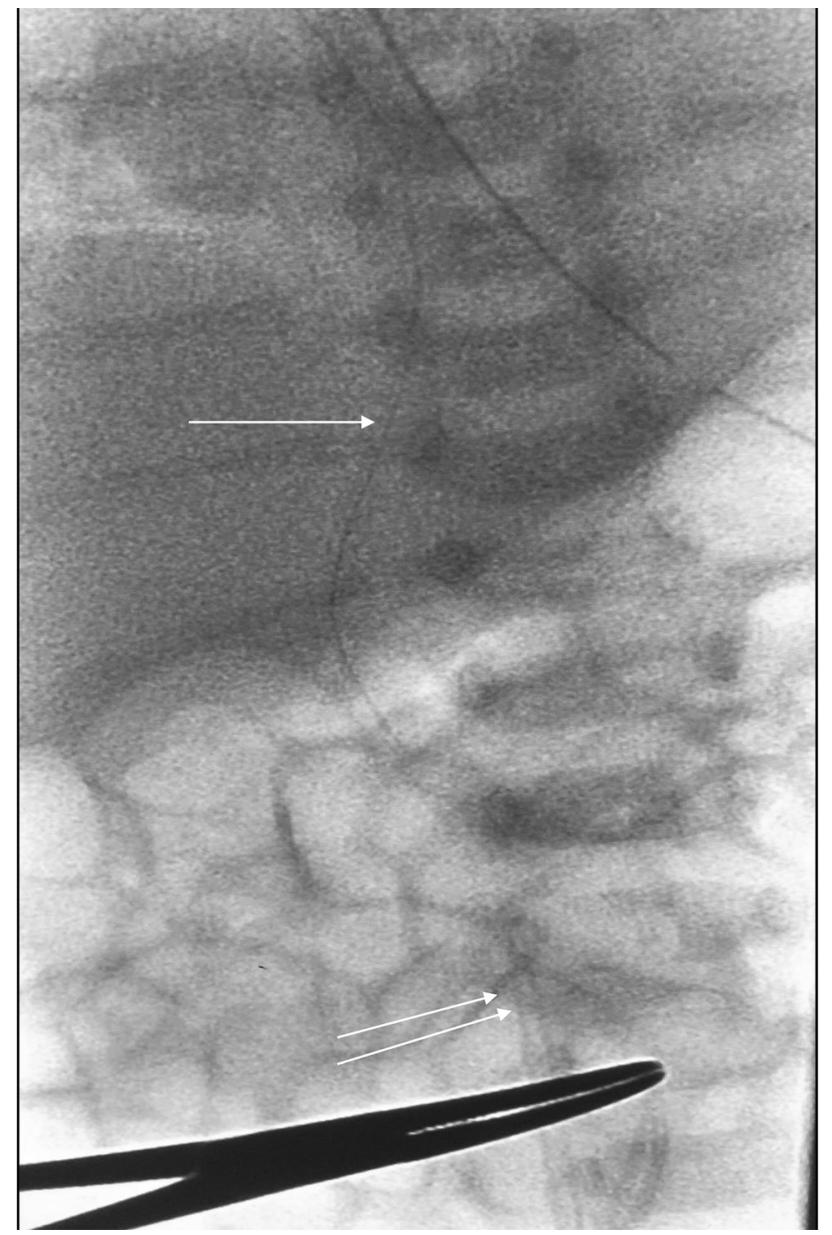

Fig. 1 Fluoroscopy image showing sheath (double arrows) touching the umbilical catheter (single arrow).

the wire was most likely to travel within rather than by the side as it being the path of least resistance. As expected, the wire tracked into the umbilical vein and through the umbilical catheter. Use of $0.025^{\prime \prime}$ guidewire adds to potential risk of pushing the umbilical catheter further distally. To prevent this complication, this step was performed with due diligence and under fluoroscopic control. Over this guidewire a 6-French TR sheath (Radiofocus, Terumo Corporation) was placed into the umbilical vein with the tip of the sheath in close contact with lower end of umbilical catheter. Subsequently a 0.014" guidewire (VersaTurn F, Abbott Vascular) was passed alongside the previous guidewire into the umbilical catheter, this step was made easy by close proximity of the sheath tip to the lower end of the umbilical catheter. The 0.025 " guidewire was removed and a $1.5-\mathrm{mm}$ monorail balloon (Ryujin Plus, Terumo Corporation) was introduced over the guidewire into the catheter lumen (-Fig. 2). The balloon was inflated to the nominal pressure and after confirming good grip over the catheter by the inflated balloon the whole assembly was retrieved with balloon inflated within ( - Fig. 3). Fluoroscopy and visual inspection of the catheter confirmed complete recovery of the catheter ( $\boldsymbol{- \text { Fig. }} \mathbf{4}$ ). Since the umbilical vein was collapsed, use of intravascular forceps was not considered as first option as this would require a larger sheath and

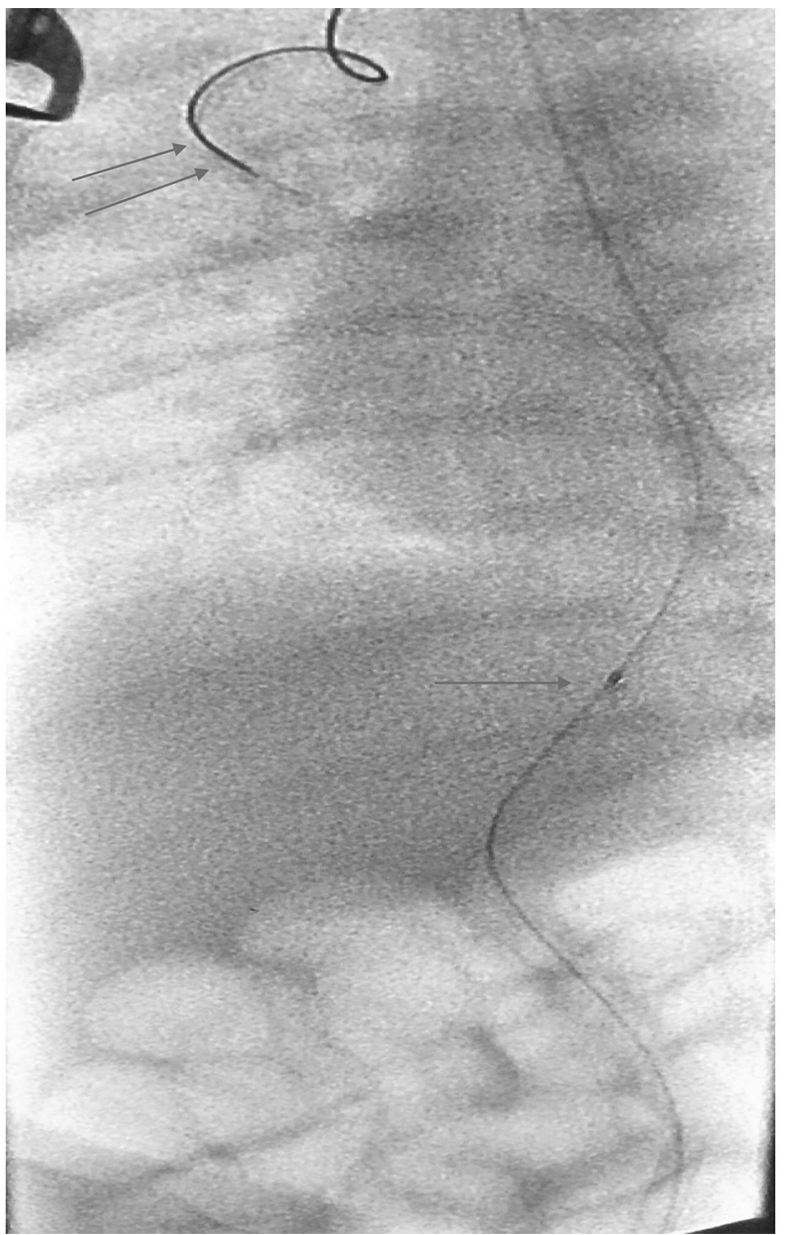

Fig. 2 Fluoroscopy image showing 0.014 guidewire (double arrows) in the catheter with $1.5-\mathrm{mm}$ balloon (single arrow) inside the catheter.

more space around the catheter to manipulate the forceps within the vessel.

Subsequent to the retrieval the neonate had uneventful recovery and was discharged on day 2 post procedure.

\section{Discussion}

Retrieval of the foreign body in pediatric population is a challenge due to radiation concerns, small size of vessels, and limitations in terms of hardwares. There are several vascular techniques described for retrieval of intravascular foreign bodies. The most commonly used technique is to grip the foreign body from outside using a snare or forceps. ${ }^{1}$ Sometimes the foreign bodies are deliberately displaced from original position to bring them to favorable position using balloons, at times stone retrieval baskets ${ }^{2}$ are also used for intravascular foreign body retrieval., ${ }^{3,4}$ These techniques work well in relatively large size and distended vascular channels as there is enough space around the foreign body to maneuver the hardware to obtain a good grip for its retrieval. Woodhouse and Uberoi in their article had described a similar technique for intravascular foreign body retrieval using guidewire, and inflating a low profile balloon within to grasp the foreign body. ${ }^{2}$ In this case we could use the small collapsed vessel 


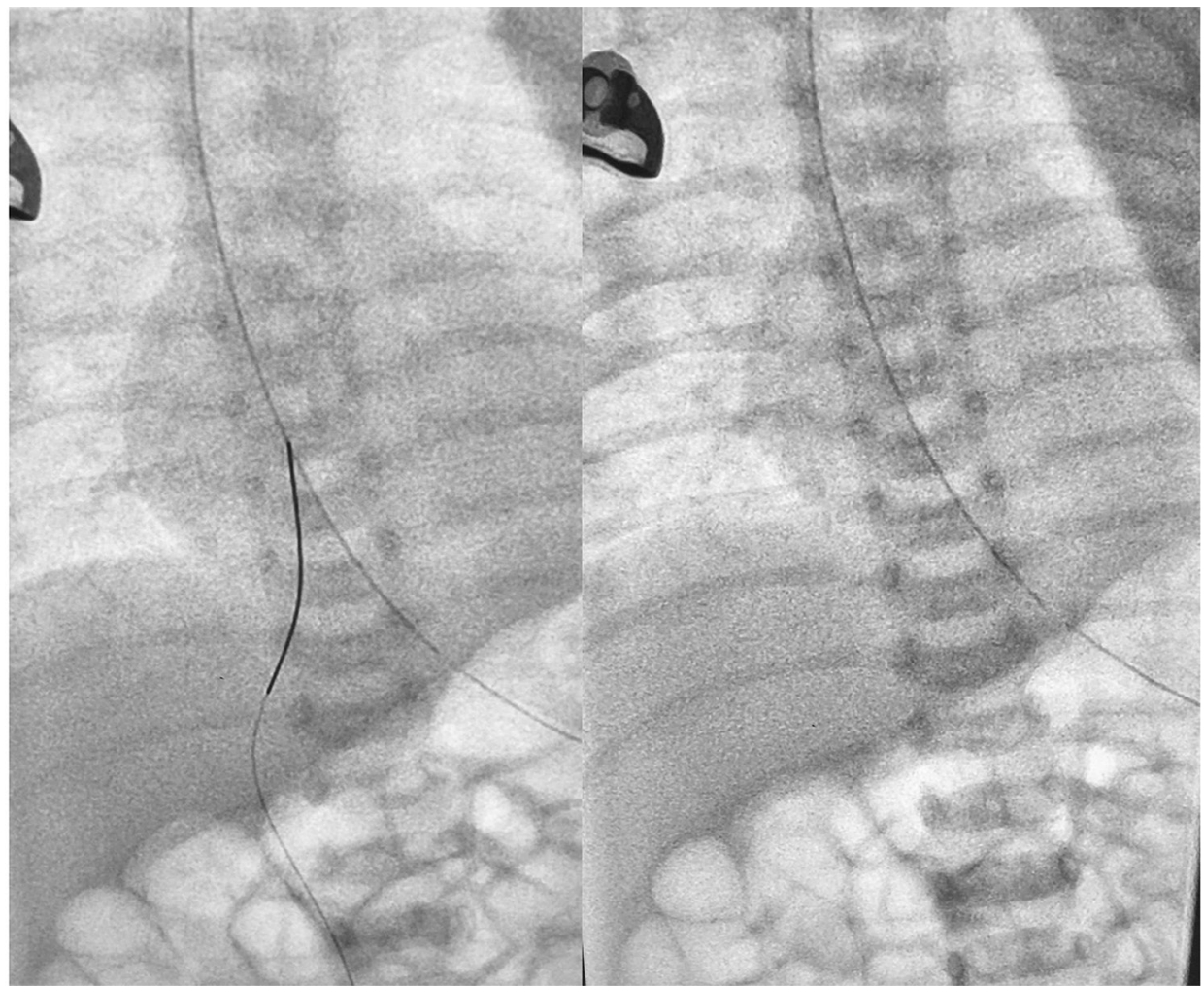

Fig. 3 Fluoroscopy image showing wire along with catheter removed with inflated balloon. Final image showing complete retrieval of catheter.

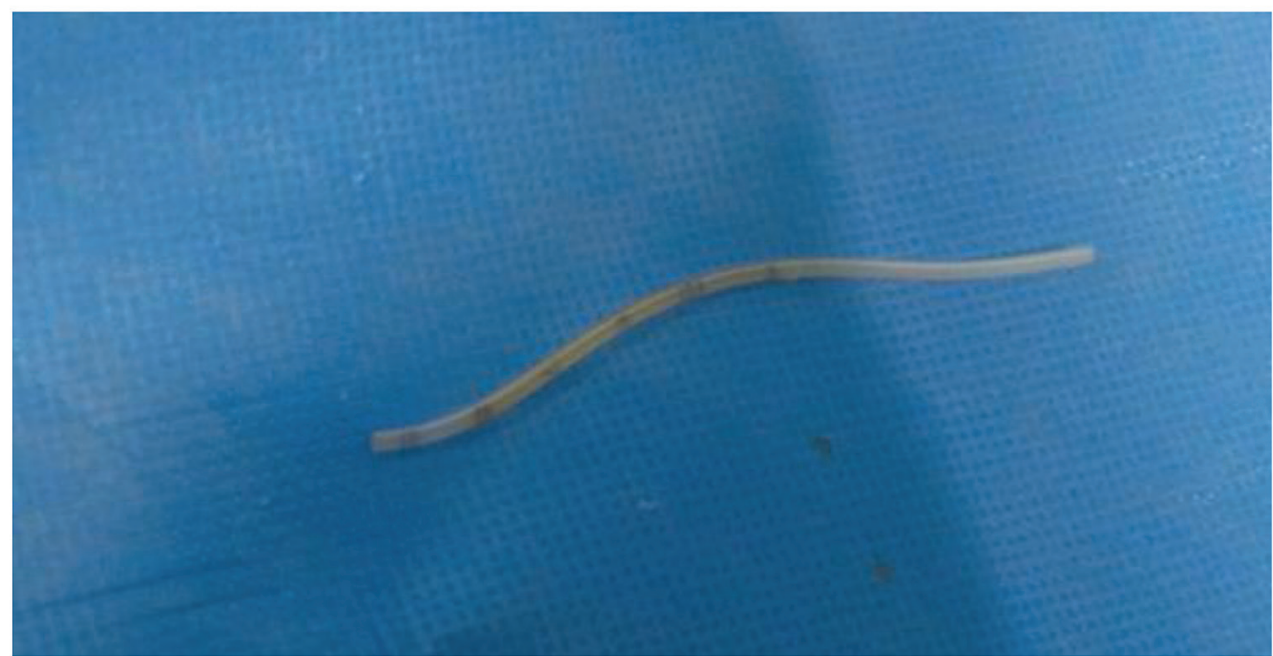

Fig. 4 Photograph of retrieved catheter.

to our advantage by cannulating the catheter from within to achieve a grip over the catheter, followed by its subsequent successful retrieval.

\section{Conflict of Interest}

None.

\section{References}

1 Egglin TK, Dickey KW, Rosenblatt M, Pollak JS. Retrieval of intravascular foreign bodies: experience in 32 cases. AJR Am J Roentgenol 1995;164(5):1259-1264
2 Woodhouse JB, Uberoi R. Techniques for intravascular foreign body retrieval. Cardiovasc Intervent Radiol 2013;36(4):888-897

3 Lawrence PF, Schechter MA, O'brien PJ, Cox MW. Evidence summary Retrieval of iatrogenic intravascular foreign bodies. YMVA 2013;57:276-281

4 Schechter MA, O'Brien PJ, Cox MW. Retrieval of iatrogenic intravascular foreign bodies. J Vasc Surg 2013;57(1):276-281 